\title{
The STaR Program Continues to Rise
}

\author{
Barbara Reys and Robert Reys
}

An award from the National Science Foundation helped establish a program for early-career mathematics educators as they transition from completion of a doctoral program to a faculty position in an institution of higher education [1]. The program name $(\mathrm{STaR})$ is derived from its focus on Service, Teaching, and Research. The program was initially modeled on Project NExT, a successful induction program for mathematicians entering careers in institutions of higher education, but it has subsequently established its own identity. This article provides a status report about the program.

Who can participate? The STaR program is open to anyone completing a doctorate in mathematics education and who is in their first or second year of a tenure-track position in mathematics education at an institution of higher education. The academic appointment can be in either a mathematics department or in a college or school of education. Typically thirty to thirty-five STaR Fellows are accepted each year based on available funds. In order to apply, the applicant must confirm support from their department chair or dean indicating the home institution's willingness to provide travel funds for the applicant to attend the summer institute and a follow-up meeting that coincides with

Barbara Reys is Curators' Professor of Mathematics Education at the University of Missouri-Columbia. Her email address is reysb@missouri . edu.

Robert Reys is Curators' Professor Emeritus of Mathematics Education at the University of Missouri-Columbia. His email address is reysr@missouri .edu.

For permission to reprint this article, please contact: reprint-permission@ams.org.

The STaR Program is funded by the National Science Foundation under grant No. 0922410. The opinions expressed are the authors', and this article does not reflect any endorsement by the National Science Foundation.

DOI: http://dx.doi.org/10.1090/noti1277 the annual meeting of the Association of Mathematics Teacher Educators (AMTE). The STaR Fellows are provided lodging and some meals during the summer institute. The application process is announced each fall through the AMTE website and newsletter, as well as in the MAA Focus. Application review occurs in the fall with notification to applicants in January.

What happens during the summer institute? Prior to the five-day institute, STaR Fellows are asked to identify their teaching and research interests. While research interests vary, most fall into areas such as teacher knowledge/beliefs, teacher preparation, student learning, instructional materials/curriculum, and equity/diversity; whereas teaching interests tend to fall along traditional lines, such as courses directed toward elementary, middle, or secondary teacher education candidates (undergraduate and graduate level).

Four to six staff members-typically, mid- and senior-career mathematics educators-facilitate the institute. The institute consists of plenary sessions on teaching, research, and service that are led by the staff. In addition to the plenary sessions, special interest groups are established that focus on research and teaching. For example, STaR Fellows teaching courses (content or methods) that are targeted toward middle school teachers meet to discuss what they are doing, share syllabi, discuss challenges they face, and exchange ideas about teaching these courses. These special interest groups continue to dialogue during the year as they teach comparable courses. In a similar manner, research groups are formed that allow STaR Fellows to meet with other mathematics educators sharing similar research interests. These meetings might result in STaR Fellows designing and conducting a joint research effort across multiple institutions, and sometimes this work 
evolves into proposals for funds to support their collaborative research.

In addition, each STaR Fellow is asked to prepare a manuscript prior to the institute so that it can be read by the staff and other STaR Fellows who have a similar interest. The manuscript may be targeted toward teachers or researchers, but often is based on their dissertation. These manuscripts are then critiqued, discussed, and frequently revised during the institute. Continued work on these manuscripts has resulted in many scholarly publications by the STaR Fellows, some of which are coauthored with other STaR Fellows.

There is also free time during the institute that allows for continued discussion on topics of mutual interest. The personal networking established during the institute and continued throughout the years following the institute is a particular strength of the program, as many Fellows work in isolation at their home institution (e.g., they may be the only mathematics educator in their department). Fellows also meet again at the annual meeting of AMTE.

Who are the STaR Fellows? The majority of STaR Fellows have prior teaching experience in $\mathrm{K}-12$ classrooms, but they come with different backgrounds and interests. About two-thirds of the STaR Fellows are female. About one-half of them have a master's degree or the equivalent in mathematics completed prior to or as a part of their doctoral preparation. Thus far, STaR Fellows have completed doctoral programs in seventy-two different institutions of higher education, most of which are in the USA (Table 1). However, the variability of doctoral programs in mathematics education has been well documented [3], [4], so the doctoral graduates enter the STaR program with a wide range of knowledge, interest, and backgrounds. Furthermore, their career goals vary, as about one-half of the STaR Fellows have their tenure home in mathematics departments, typically teaching a range of mathematics courses and courses targeted toward future K-12 teachers [2], whereas STaR Fellows in colleges/schools of education are teaching methods courses for K-12 teachers, supervising interns in K-12 schools, teaching graduates courses in mathematics education, and typically working in institutions that have doctoral programs in mathematics education.
Table 1. Institutions from which STaR Fellows received their doctorate and the number of graduates from these institutions.

\begin{tabular}{|c|c|}
\hline Arizona State University (4) & University of Central Florida (4) \\
\hline Auburn University & University of Cincinnati \\
\hline Baylor University & University of Colorado \\
\hline Boston College & University of Delaware (7) \\
\hline Boston University (4) & University of Florida \\
\hline Brigham Young University & University of Georgia (16) \\
\hline Florida State University & University of Houston \\
\hline Georgia State University (2) & University of Illinois-Chicago (2) \\
\hline Harvard University & University of Illinois-Urbana (2) \\
\hline Illinois State University (6) & University of Kansas \\
\hline Indiana University (8) & University of Kentucky (2) \\
\hline Iowa State University & University of London (Education Institute) \\
\hline Kennesaw State University & University of Louisville \\
\hline Kent State University & University of Maryland (5) \\
\hline Mercer University & University of Miami \\
\hline Michigan State University (11) & University of Michigan (2) \\
\hline Montana State University (2) & University of Minnesota (7) \\
\hline North Carolina State University (11) & University of Missouri (8) \\
\hline Ohio University (2) & University of Nebraska (2) \\
\hline Oklahoma State University (3) & University of Nevada-Reno (2) \\
\hline Oregon State University (2) & University of North Carolina-Chapel Hill (4) \\
\hline Portland State University (2) & University of North Carolina-Charlotte (2) \\
\hline Purdue University & University of North Carolina-Greensboro \\
\hline San Diego State University/UC-SD (5) & University of Northern Colorado (6) \\
\hline Stanford University (2) & University of Pittsburgh (5) \\
\hline Teachers College, Columbia University (4) & University of South Florida (4) \\
\hline Texas State University-San Marcos (3) & University of Tennessee \\
\hline The Ohio State University & University of Texas-Arlington \\
\hline The Pennsylvania State University (5) & University of Texas-Austin (2) \\
\hline University at Buffalo & University of Virginia (2) \\
\hline University of Alberta & University of Washington (2) \\
\hline University of Arizona (4) & University of Wisconsin (5) \\
\hline University of California-Berkeley (4) & Vanderbilt University (2) \\
\hline University of California-Davis & Virginia Tech (2) \\
\hline University of California-Los Angeles & West Virginia University \\
\hline University of California-Santa Cruz & Western Michigan University (2) \\
\hline
\end{tabular}

From 2010 to 2015 a total of 210 STaR Fellows have entered or completed the program. They are employed in 144 different institutions of higher education in 42 states, ranging from private liberal arts to public regional institutions to heavily research-oriented universities (Table 2, see next page). The 144 institutions are distributed across a wide range of Carnegie Classification. In fact, over half of the STaR Fellows (almost 60 percent) are faculty members in institutions that award doctoral degrees, as shown by the DRU, RU/H, and $\mathrm{RU} / \mathrm{VH}$ in Table 3. Thus, the STaR Fellows find themselves in institutions with a wide range of expectations with regard to teaching, research, and service.

What do the STaR Fellows say about their STaR experience? The STaR program has led to many collaborations leading to joint work on

Table 3. A summary of the Carnegie Classification* of the institutions where STaR Fellows had their initial academic appointments.

\begin{tabular}{|l|l|l|l|l|l|l|l|l|l|}
\hline Carnegie & $\begin{array}{l}\text { Asso/Pub- } \\
\text { U-MC }\end{array}$ & Bac/Diverse & Bac/A\&S & MastersS & MastersM & MastersL & DRU & RU/H & RU/VH \\
\hline \#institutions & 1 & 3 & 9 & 4 & 7 & 63 & 16 & 41 & 66 \\
\hline \%institutions & 0.5 & 1.4 & 4.3 & 1.9 & 3.3 & 30.0 & 7.6 & 19.5 & 31.4 \\
\hline
\end{tabular}

*A complete description of the Carnegie Classification is available at carnegieclassifications. iu.edu/descriptions/basic.php 
Table 2. Institutions where STaR Fellows were employed when they participated in the STaR Program.

\begin{tabular}{|c|c|}
\hline Appalachian State University (2) & Rowan University \\
\hline ArizonaState University & San Diego State University \\
\hline Arkansas State University & Sonoma State University \\
\hline AuburnUniversity & Southeast Missouri State University \\
\hline Bemidji State University & Southern Methodist University (2) \\
\hline Berry College (2) & SouthernUtah University \\
\hline Black Hills State University & St. John Fisher College \\
\hline Boise State University & Teachers College, Columbia University \\
\hline Boston College & Texas A\&MUniversity-Corpus Christi \\
\hline Boston University (3) & Texas A\&MUniversity-San Antonio \\
\hline Bowling Green State University (2) & Texas A\&M-Commerce \\
\hline Bridgewater State University & Texas Christian University \\
\hline Brigham Young University & The College of New Jersey \\
\hline Bucknell University & The Ohio State University \\
\hline Buffalo State University of New York & The University of Texas-Pan American \\
\hline Cal Poly University-San Luis Obispo & Towson University (2) \\
\hline California Polytechnic University (2) & Tuskegee University \\
\hline California State University, Chico (2) & Univ. of South Florida-Sarasota Manatee \\
\hline California State University, Long Beach & University of Georgia \\
\hline Central Michigan University & University of Alabama (3) \\
\hline City University of New York-BMCC & University of Arizona (3) \\
\hline Clemson University (2) & University of Arkansas \\
\hline Colorado State University & University of Central Arkansas \\
\hline Drake University (2) & University of Central Missouri (2) \\
\hline East Carolina University (2) & University of Cincinnati (2) \\
\hline Eastern Kentucky University (2) & University of Colorado, Denver \\
\hline FayettevilleStateUniversity & University of Delaware(2) \\
\hline Florida State University (2) & University of Denver \\
\hline George Mason University & University of Georgia (2) \\
\hline GeorgiaSouthern University & University of Idaho \\
\hline Georgia State University & University of Illinois at Chicago \\
\hline Hood College & University of Illinois, Urbana-Champaign \\
\hline Hunter College, CUNY & University of Indianapolis (2) \\
\hline Illinois Institute of Technology & University of Kentucky (3) \\
\hline Illinois State University (3) & University of Louisville \\
\hline Indiana State University & University of Massachusetts, Amherst \\
\hline IowaState University & University of Memphis \\
\hline Ithaca College & University of Mississippi \\
\hline IUPUI(2) & University of Missouri (2) \\
\hline James Madison University (2) & University of Missouri-St. Louis \\
\hline Kansas State University & University of Montana \\
\hline Keene State College (2) & University of Nebraska-Lincoln \\
\hline Kennesaw State University (7) & University of Nevada, Las Vegas \\
\hline Kent State University (2) & University of New Hampshire \\
\hline Lehman College (CUNY) (2) & University of New Mexico \\
\hline Longwood University & University of North Carolina-Chapel Hill \\
\hline McDaniel College & University of North Carolina Wilmington \\
\hline Metropolitan State College of Denver & University of North Florida \\
\hline Miami University (2) & University of North Texas at Dallas \\
\hline Michigan State University (2) & University of Northern Iowa (3) \\
\hline Middle Tennessee State University (2) & University of Oklahoma \\
\hline MidwesternState University & University of Pittsburgh \\
\hline Millersville University (2) & University of South Carolina (5) \\
\hline MontanaState University-Bozeman & University of South Florida (3) \\
\hline Montclair State University (4) & University of Southern Indiana \\
\hline North American University & University of St. Thomas \\
\hline North Carolina State University & University of Texas At San Antonio (2) \\
\hline North Georgia College \& State University (2) & University of Washington \\
\hline Northern Arizona University & University of West Florida \\
\hline Northern Illinois University & University of Wisconsin-La Crosse \\
\hline Northern Kentucky University (2) & University of Wisconsin-Madison \\
\hline Ohio University & University of Wisconsin-Stevens Point \\
\hline Oregon State University (5) & Utah State University \\
\hline Penn State Berks & Virginia Tech University (2) \\
\hline Penn State Harrisburg & Washington State University (2) \\
\hline Penn State University & Weber State University, Ogden, UT \\
\hline Penn State University-Abington College & West Chester University (2) \\
\hline Pepperdine University & West Virginia University \\
\hline Portland State University & Western Washington University \\
\hline PurdueUniversity (3) & Westminster College \\
\hline Rockhurst University & \\
\hline
\end{tabular}

teaching experiments, research projects, proposals for external funding, scholarly publications, and presentations related to various aspects of mathematics education. The feedback from each cohort of STaR Fellows has been positive, testifying to how the STaR experience has contributed to career growth. Here are several reflections offered by STaR Fellows:

"The STaR experience has provided me with the most powerful networking experience I have had so far in my career."

"This experience was a gift. I needed this opportunity at this exact moment more than I need any other type of mentoring experience.... I have direct advice from very wise mentors about how I should make decisions related to my work, and I have connections with like-minded, serious scholars who will continue this conversation with me for many years to come."

As universities struggle to provide strong mentoring experiences for young faculty, the STaR program provides a focused experience for earlycareer mathematics educators. Several Fellows have commented on the power of the program in providing them such an experience that pays off well beyond the initial institute:

"There are moments in life when you know you are taking part in something great. I can honestly say that STaR was such an experience for me."

"Many conferences and workshops provide opportunities to meet colleagues, develop relationships between institutions, craft works on research, and/or advance the profession of teaching. STaR stands apart because it does all of these things, but in a way that supports the development of junior faculty across various institutions with differing demands (both in terms of work and culture). It is a significant and critical contribution to our profession."

What is the future of the STaR Program? Just as Project NExT has served mathematicians entering careers in higher education, the STaR Program has helped early-career mathematics educators address some of the challenges they face as they transition into their positions in higher education [2]. The success of the STaR Program encouraged the leadership to seek a permanent home within a professional organization that would allow the STaR Program to continue beyond NSF support, and the AMTE agreed to serve that role. Financial support for the program has come from private foundations, professional organizations, and many individuals, including STaR Fellows and AMTE members. Information about contributing to the STaR program is available at https:// amte.net/civicrm/contribute/transact?reset $=1 \& i d=13$.

In summary, each generation of scholars has a responsibility to help educate and prepare their successors in the discipline. The STaR Program 
is an effort to help initiate the next generation of mathematics educators, providing support for them to develop networks that can help them launch and establish a productive career. We appreciate the vision of the National Science Foundation for supporting the establishment of the STaR Program and the commitment of AMTE for continuing the effort.

\section{References}

1. B. REYS and R. REYS, Supporting the next generation of "stewards" in mathematics education, Notices of the American Mathematical Society 59 (2012), no. 2, 288-290.

2. R. Reys, D. Cox, S. Dingman, and J. Newton, Transitioning to careers in higher education: Reflections from recent $\mathrm{PhDs}$ in mathematics education, Notices of the American Mathematical Society 5 (2009), no. 9, 1098-1103.

3. R. REYs and J. KilPATRICK (eds.), One Field, Many Paths: U.S. Doctoral Programs in Mathematics Education, Washington, D.C.: American Mathematical Society/ Mathematical Association of America, 2001.

4. R. Reys and J. Dossey (eds.), U.S. Doctorates in Mathematics Education: Developing Stewards of the Discipline, Washington, DC: American Mathematical Society/Mathematical Association of America, 2008.
American Mathematical Society

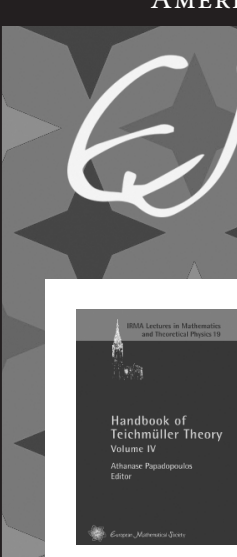

European Mathematical Society

attempt to present various aspects of this theory with its relations to fields, including, but not limited to, Riemann surface theory, low-dimensional topology, partial differential equations, and mathematical physics.

IRMA Lectures in Mathematics and Theoretical Physics, Volume 19; 20 I4; 838 pages; Hardcover; ISBN: 978-3-037/ 9-I I7-0; List US\$128;AMS members US\$102.40; Order code EMSILMTP/I 9

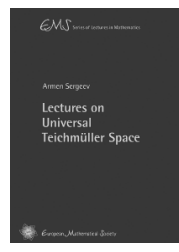

LECTURES ON UNIVERSAL TEICHMÜLLER SPACE

Armen N. Sergeev, Steklov Mathematical Institute, Moscow, Russia

Based on a lecture course given by the author, this book is designed for a one-semester course for undergraduate students familiar with basic differential geometry and complex functional analysis.

EMS Series of Lectures in Mathematics, Volume 19; 2014; 111 pages; Softcover; ISBN: 978-3-037/9-14I-5; List US\$32; AMS members US $\$ 25.60$; Order code EMSSERLEC/19

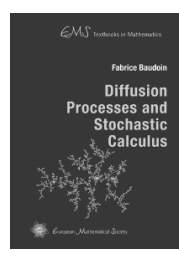

DIFFUSION PROCESSES AND STOCHASTIC CALCULUS

Fabrice Baudoin, Purdue University, West Lafayette, IN

Intended for students, or even researchers, who wish to learn the basics of the theory of continuous stochastic processes in continuous time, the purpose of this book is to present the most important aspects of this theory and to introduce some of its ramifications.

EMS Textbooks in Mathematics, Volume 16;2014; 287 pages;

Hardcover; ISBN: 978-3-03719-133-0; List US\$68; AMS members US\$54.40; Order code EMSTEXT/16

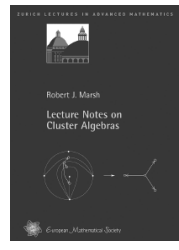

\section{LECTURE NOTES ON} Cluster AlgEBRA

Robert J. Marsh, University of Leeds, United Kingdom

The aim of these notes is to give an introduction to cluster algebras which is accessible to graduate students or researchers interested in learning more about the field while giving a taste of the wide connections between cluster algebras and other areas of mathematics.

Zurich Lectures in Advanced Mathematics, Volume 19; 2014; 122 pages; Softcover; ISBN: 978-3-037| 9-130-9; List US\$36; AMS members US\$28.80; Order code EMSZLEC/ 19

Publications of the European Mathematical Society (EMS). Distributed within the Americas by the American Mathematical Society.

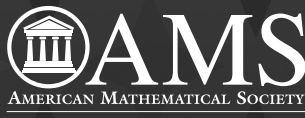

Order Online: www.ams.org/bookstore

Order by Phone:

BOOKSTORE 